\title{
nature
}

nanotechnology

\section{Small is different}

\author{
Nanoscience and nanotechnology offer fundamental challenges in research and the possibility of a \\ new industrial revolution. This presents opportunities for all sorts of scientists and engineers.
}

Depending on who you ask, nanotechnology started in 1981, 1974, 1959 or the Bronze Age. And depending on who you believe, and the definitions they use, the world market for nanotechnology products will be worth $\$ 2,600$ billion in 2014 , or $\$ 1,000$ billion in 2015 .

There is, however, consensus about some matters. First, for something - a material, device, system or process - to be truly nano, the relevant length scale must be small enough for its properties and behaviour to be different from those observed in the bulk. Second, nanoscience and nanotechnology are genuinely multidisciplinary and broad-based subjects. At the recent International Conference on Nanoscience and Technology in Basel, for instance, it was notable that most of the plenary speakers were active in many different areas of nano: it is not uncommon for a group to be working on nanowirebased biosensors and and, say, devices for quantum-information processing at the same time. Third, governments and companies around the world are not investing billions in the field because the science is fascinating - they will want to see returns on their investments.

Although large numbers of scientists and engineers have embraced the opportunities and challenges offered by nanotechnology, some have preferred to complain from the sidelines. It is true that many researchers have rebranded what they have been doing for years as nano, but there is nothing new about scientific communities reinventing and renaming themselves - from solidstate physics to condensed-matter and materials physics, for example, or from geology to earth science.

It is also true that a small amount of less-than-top-quality work might have been funded as a result of nanolargesse, but this is a small price to pay for the investment that has poured into basic scientific research under the banner of nanotechnology in recent years. Moreover, this has not been 'virtual' money to allow existing groups to form networks and 'virtual laboratories', as has happened with many multidisciplinary programmes in the past, but new money for building new laboratories and facilities to explore material and processes on the smallest length scales.

There have also been critics from outside the world of science, but progress on tackling the environmental, health and safety aspects of engineered nanoparticles has been embarrassingly slow. For instance, the chair of the House Science Committee in the US Congress, Sherwood Boerhlert, recently criticized government agencies for the lack of progress they had made on this issue. "We're on the right path to dealing with the problem," said Boehlert, "but we're sauntering down it at a time when a sense of urgency is required". Another committee member was less diplomatic, describing a report from the Nanotechnology Environmental and Health Implications working group as "juvenile". There is clearly an urgent need for environmental, health and safety issues to move up the nanotechnology agenda before governments, never mind the public, lose their patience.

This broader picture, including toxicology and the social impact of nanotechnology, is explored in the 'front half' of this first issue of Nature Nanotechnology. The research papers, meanwhile, reflect the breadth of current work in nanoscience and nanotechnology. From silicon nanowires to switches based on the tobacco mosaic virus, and from a nanoplasmonic ruler for measuring various properties of DNA to the electronic properties of carbon nanotubes, they show that small really is different.
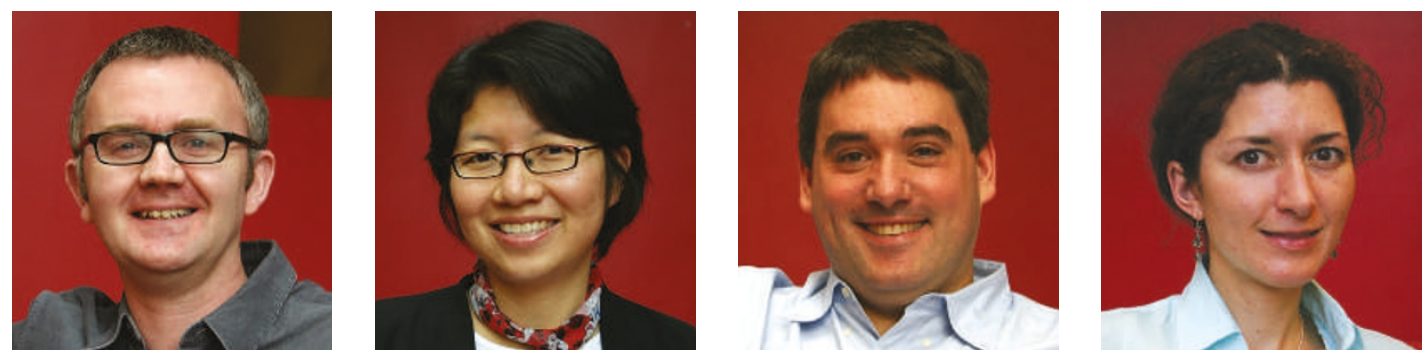